\title{
Analysis of the Relationship between Patent Litigation and Citation: Subdivision of Citations
}

\author{
Jiyoun Lim* \\ SW/Contents Future Research Team, Electronics and Telecommunications Research Institute (ETRI), 218 Gajeong-ro, Yuseon-gu, \\ Daejeon, 305-700, Korea
}

Received: 21 Sep. 2012, Revised: 19 Dec. 2012, Accepted: 20 Dec. 2012

Published online: 1 Sep. 2014

\begin{abstract}
Recent examples of patent litigation show the evidence of firms strategic patent use. Thus forecasting patent litigation becomes a greater priority. Patent citations have been prevalent in its usage in analyzing business environment as diverse patent indicators or a tool to predict patent litigation. However, most previous research has considered only direct patent citations. In order to overcome the limitation, this study analyzes patent litigation quantitatively through three kinds of patent citations: direct, indirect and latent citation, and empirically analyzed the relationship between these citations and patent litigation between plaintiff and defendant firms based on U.S. patent documents and patent litigation information. Consequently, this study found that the indirect citation is more by $7 \%$ than direct citations to patent litigation. In addition, latent citation is $8 \%$ higher in frequency compared with the number of litigations in in/direct citation relationship. Therefore, these results indicate that various approach for patent citation can provide more information for forecasting patent litigation.
\end{abstract}

Keywords: Patent litigation, patent citation, indirect citation, latent citation

\section{Introduction}

Patents have been long regarded a tool which legally guarantees a firm's exclusive rights to a newly development technology from other competitors. But recently patents began to carry much more complex and varied implication $[1,2]$. The patent can be used for the analyses of technology industry as a strategic measure for technology planning [3]. The most recent example of this phenomenon is the smart-phone lawsuit. Motorola sued Apple in October, 2010 which has itself been sued by Microsoft a few days ago, Apple sued HTC and Microsoft filed a lawsuit against Motorola. A business software maker, Oracle has sued Google, Kodak which used to make cameras sued Apple and there are many other mobile-phone-related patent complaints. Interestingly, most suits were filed by patent owners who hail from another industry. Because the legal relationship between industries has become more complicated as the distinctions between digital products are disappearing as technologies converge and overlap $[4,5,6]$. It is evident in drastic increase in patent litigations resulting from the firm's recognition of patent as essential element of intellectual property and its efforts to generate further benefits [7]. In 2000, the United States Patent Trademark Office (USPTO) granted about 180,000 patents. In the same year about 2,000 patent lawsuits were filed involving about 3,000 patents. The number of patent sues filed has doubled in the 1990's [8]. Firms solely specializing in patent litigation appeared subsequently and soon conflicts between regional firms turned into an international patent litigation [9]. Therefore, patents are now regarded as a vital factor in protecting the firm's own technology and forecasting patent litigation becomes a greater priority in firm's activities.

With growing number of patent litigations, studies have been conducted to analyze patent litigation from various perspectives. Some of these studies aimed to predict and prevent future patent litigations by analyzing characteristics of patents that have been sued frequently. Based on patent indicators, the researchers examined data by each field of technology $[10,11]$, citations, number of claims, family size, and other factors to identify the characteristics of a type of patent most prone to litigations [12] and proposed a model for analyzing the potential patent litigation [13]. Most of these studies relied on patent indicators and it was found that more frequently

\footnotetext{
*Corresponding author e-mail: kusses@etri.re.kr
} 
cited patents are more likely to get involved with litigation $[10,11]$.

However, these studies face several limitations. First, because the researchers only focused on constant quantity of patent being cited or citing others, they have neglected to consider relation among patent citation applicant. Lacking various perspective, it is not easy to succeed in explicating the variety between the plaintiff and the defendant on just the direct citation alone. Second, as these studies only applied direct citation into analysis, it is difficult to assume a various relation between patents in plaintiff and defendant's possession based on citation.

Accordingly, the purpose of this study is to suggest objective way such as data based indicators which can explore the litigable patents. Thus, this study isn't just about analyzing direct citation of a patent document or the relations between the firms that possess them, but also extending to analysis of the plausibility of patent litigation using various indirect citation relationships. To achieve this, Types of citations were arranged three concepts such as direct citation (1 depth), indirect citation ( 2 depth, 3 depth) and latent citation based on citation relations for the parties to a suit that plaintiff and defendant. Then this study will analyze the litigations regards to each type of citation by using the actual litigation data provided by WestLaw.

\section{Related Works}

Similar to a patent citation in any other academic paper, patent citation serves as a reference to a previously published work with the purpose of acknowledging the relevance of the works of others to matter on hand with emphasis on novelty, non-obviousness, and practicality of an invention [14]. This citation, deriving mostly from previously published dissertation and granted patent, is submitted by patent applicants and patent examiners. In any given patent $\mathrm{A}$ which include patent $\mathrm{B}$ in its reference field, patent A becomes a forward citation while the cited patent B becomes a backward citation. Therefore the forward citation and the backward citation are on the opposite ends $[15,16]$. Researchers have established that when a patent asserts a direct relationship to the other patents in its reference field of the patent document, the relation is termed direct citation.

Direct patent citation has been prevalent in its usage in patent related researches. It is to be noted that citation has been utilized as source indicators to quantitative measure of various characteristics and properties of the patent holder ranging from private to corporate and national level. For instance there is citations received per patient, which measures the influence of national or corporate patent that has had on technological innovation [17] and a proposition for Patent Count Weighted by Citation, which reflects the firm's innovative efforts [18, 19]. Other examples include Current Impact Index, which portrays citation frequency according to category of technology or industry [20,21], and Technology Strength, which supplies information on engineering influence and competence in consideration of engineering quality and quantity [22, 23, 24].

With the increase in patent litigations, researchers examined citations along with various patent indicators to forecast litigations or analyze their characteristics. Cremers (2004) statistically analyzed citation, number of claims, and family size to identify the characteristics of patents most prone to litigations [12]. Kim et al., (2002) proposed a model for analyzing the possibility of patent litigation in the foreseeable future utilizing these indicators [13]. Several literatures indicate that the more frequently cited patent is more likely to get involved in litigation $[25,10,11]$.

However these literatures based on citation face several limitations. First, the patent indicators based on citation utilize frequency of citation which cites or is cited by one another. Specifically, citation taken into account to analyze patent litigations is calculation of forward or backward citation frequency. In short, it fails to consider the relationship between the plaintiff and the defendant. Therefore this study considers analyzing the relationship between two sides in accordance with citation. The finding of the previous literature, the frequency of forward and backward citation exhibiting direct correlation to occurrence of litigation, will be considered in the aspect of the defendant opting forward citation and in the aspect of the plaintiff opting backward citation for further analysis. Therefore, the hypothesis assumes that litigation occurs when individuals involved in the litigation share a direct citation relationship. Second, the patent citations employed in the previous research strictly observed the direct relationship between forward and backward cited patents.

To complement these limitations, indirect citations can be considered. Wartburg et al. (2005) emphasized the importance of indirect citation in network analysis based on patent [14]. Atallah and Rodrguez (2006) insisted that indirect citation provide better method to measure patent quality [26]. Indirect citation is illustrated in Figure 1 where a patent (\#4) directly cite a patent \#3 which cites a patent \#2.Given the case of patent \#4, patent \#3 becomes the directly cited patent in regards to patent \#4 and its citation depth is named depth 1 . In this fashion patent \#2, which patent \#3 directly cited, is perceived as an indirectly cited patent with depth 2 on the part of the patent \#4 and patent \#1 is identified as an indirectly cited patent with depth 3 . Patent \#3, \#2, and \#1 are tagged as indirectly backward citations in regards to patent \#4. Similarly patent \#1 would identify patent \#2, patent \#3 with a depth of 2 , and patent \#4 with depth of 3 as indirectly forward citations. In other word, depth 1 means direct citation while citation over depth 2 is indirect citation and there is a transivity between indirect citations that if $\mathrm{A}-\mathrm{B}$ and $\mathrm{B}-\mathrm{C}$ citation relationships exist, then $\mathrm{A}-\mathrm{C}$ citation relationship depends on the relationship in $\mathrm{B}$ with $\mathrm{A}$ and $\mathrm{C}$. Accordingly, this study hypothesized that 


\section{Indirect Citation}

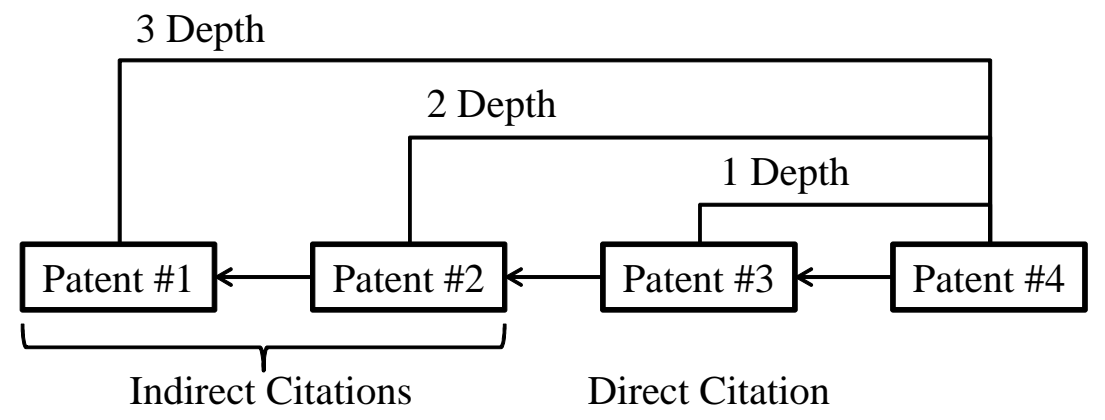

Latent Citation

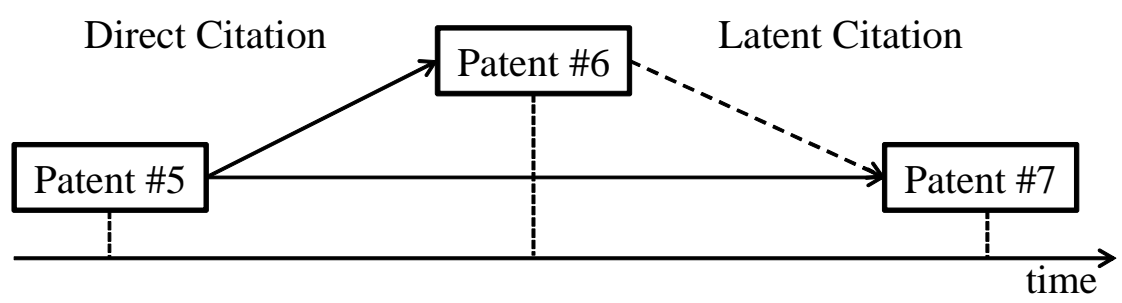

Fig. 1: Direct / Indirect Citation and Latent Citation

indirect citation would indicate significant relativity toward patent litigation as well as direct citation.

Finally, although it is conceivable for two patents to share a citation relation, a case was considered where direct relation is not found in reference field will be indirectly indicated in the later patent application. Generally, a patent application is published after one year and six months from the application filling date or the priority date without fail. And then, only these published patents can be subjected to citation by others. If a former patent application is not opened in regards to patent reference submission date, or if the patent applicant intentionally or unintentionally omits a related former patent in the reference, or if the patent examiner fails to record them in the reference, the relation between the patent and its related former patent is not observed even if the relation can be possibly ascertained later.

This potential relation between two patents can be revealed through sharing a parent patent. In other words, in a case where two patents that has not explicit citation relation shares a direct forward citation specific patent, the patents are reckoned to have significant relation ascribing to the backward citation patent. In this instance, the two patents' relation is defined as latent citation relationship.
In Figure 1, there are 3 patents for explaining latent citation which patent \#5 was applied first, then patent \#6 applied and lastly patent \#7 applied. As shown in Figure 1, patent \#7 \& \#5 and patent \#6 \& \#5 maintain direct citation relationship. Though in the given situation patent \#7 and patent \#6 does not share a direct citation relationship, nevertheless patents shares direct citation patent \#5. For case in which a patent without a direct citation relationship shares direct citation specific patent like patent \#5, it is established that their relationship would be a potential citation relationship. If the application date of patent \#6 precedes application date of patent \#7, patent \#6 will become backward potential citation patent to patent \#7 [27]. Contrary to Lee et al. (2004), who designated the citation relationship as one of indirect citation, this study has named it latent citation in order to distinguish it from aforementioned indirect citation. Therefore this study will analyze the case of right holder of the patent \#6 suing the right holder of another patent that cite patent \#6 and assess whether the litigation carry significance to the right holder of patent \#7, who is in the latent citing relationship. 
Table 1: Descriptive statistics

\begin{tabular}{|c|c|c|c|c|c|c|}
\hline & \multicolumn{3}{|c|}{ WestLaw data } & \multicolumn{3}{|c|}{ Analysis data } \\
\hline & Average & S.D & Median & Average & S.D & Median \\
\hline Patent per litigation & 2.3 & 4.5 & 1.0 & 2.8 & 5.9 & 2.0 \\
\hline Defendant per litigation & 2.4 & 3.8 & 1.0 & 2.2 & 3.1 & 1.0 \\
\hline Plaintiff per litigation & 1.3 & 0.9 & 1.0 & 1.3 & 1.1 & 1.0 \\
\hline Defendant per patent & 4.5 & 12.7 & 2.0 & 3.7 & 6.9 & 2.0 \\
\hline Plaintiff per patent & 1.6 & 1.6 & 1.0 & 1.6 & 1.5 & 1.0 \\
\hline
\end{tabular}

\section{Research Methodology}

This study employed data provided by the United States legal research system Westlaw and United State Patent and Trademark Office (USPTO) from years 2003 to 2010. Westlaw is one of the primary apparatus for legal professionals in United States and is currently a subsidiary of Thomson Reuters. The patent citation information was acquired from patentpia.com, a database service provider of patents issued by USPTO.

According to WestLaw, the recorded number of litigations is 21,761 and the number of plaintiff's patents used in these litigations is 22,756 . In these litigations there are 13,342 plaintiffs and 30,144 defendants. However the number of litigations for analysis is about 13,000 , which is $60 \%$ of all litigations recorded in the database. This can be ascribed to the differing method of recording the number of plaintiffs and defendants, where abbreviations of nations or organization name such as co., corp., ltd were at times left out or were under name other than the one identified on the patent application in process of mapping WastLaw and USPTO data. Consequently, it was found that there were 7,164 plaintiffs $(54 \%)$ and 9,075 defendants (30\%) which were subsequently subjected to further analysis. The calculation of average, standard deviation, and median of WestLaw data and the analyzed data indicate minor difference between two groups (Table 1). For instance, the standard deviation of defendant per patent in WestLaw data was 12.7 and in the Analyzed data 6.9, well within the acceptable boundary. Furthermore, compared with International Patent Classification (IPC) on litigated patent document, 3,862 (67\%) litigations of 5,763 data in Human Necessities, 2,693 (68\%) litigations of 3,985 data in Performing Operations, Transporting, 1,282 (72\%) litigations of 1,779 data in Chemistry, Metallurgy, 109 (70\%) litigations of 155 data in Textiles, Paper, 665 (66\%) litigations in 1,013 data in Fixed Constructions, 1,069 (69\%) litigations of 1,552 data Mechanical Engineering, Lighting, Heating, Weapons, 4,432 (77\%) litigations of 5,759 data in Physics, and 3,122 (80\%) litigations of 3,924 data in Electricity were analyzed. To sum up, it was found that on average $71 \%(17,234)$ of 23,930 WestLaw data was used in the analysis.
Based on these litigation data and citation information from patent documents, the relationship between patent litigation and citation was analyzed. Due to the differing number of plaintiffs and defendants, the study conducted analysis with forward citation extracted from patents of the plaintiffs and backward citation extracted from patents of the defendants. This paper analyze citation information based on all patents of the defendant because the legal information offers the plaintiffs' litigated patent information on the grounds of providing evidence of litigation while doesn't the defendant's except for the appellation.

To calculate the 2 depth indirect citation, the information of citations of patent will be divided into three groups: patents of plaintiff, patents of defendants and the patents that are cited by defendant's patents and cite plaintiff's patents. This paper denotes $A_{i}$ as a patent of a defendant and $C_{k}$ as a patent of a plaintiff and $B_{j}$ as a patent that is cited by $A_{i}$ and also cites $C_{k}$, respectively. Patents of plaintiffs are those patents that are cited by defendants'. Hence, this study uses the indirect citation frequency of defendant's patents, $I D C_{k}$, which is demonstrated in Eq. (2). It was calculated by two aspects that one utilized forward citations of plaintiffs and the other utilized backward citations of defendants.

$$
\begin{gathered}
{\left[\alpha_{i j k}\right]_{M \times N \times L},} \\
\text { where } \alpha_{i j k}= \begin{cases}1 & A_{i} \text { cites } B_{j} \text { and } B_{j} \text { cites } C_{k} \\
0 & \text { otherwise }\end{cases} \\
\qquad I D C_{k}=\sum_{i=1}^{k} \alpha_{i j k}, \quad 1 \leq k \leq L
\end{gathered}
$$

In a similar way, the 1 depth and 3 depth indirect citations were calculated.

The paper calculate the frequency of latent citation through dividing the information of citations of patent into three groups: patents of plaintiff, patents of defendant and the patents that are cited by both defendant's patents and plaintiff's patents. This paper denoted $Q_{i}$ as a patent of plaintiff, $P_{j}$ as a patent of defendant and $R_{k}$ as the third party patent. $T(X)$ is debited as a time of patent 
Table 2: The number of litigated patents and the number of litigations in in/direct citing relationship

\begin{tabular}{|c|c|c|c|c|c|c|c|c|}
\hline \multirow[b]{3}{*}{1 depth (direct citation) } & \multicolumn{4}{|c|}{ The number of litigated patents } & \multicolumn{4}{|c|}{ The number of litigations } \\
\hline & \multicolumn{2}{|c|}{ Focused on plaintiff } & \multicolumn{2}{|c|}{ Focused on defendant } & \multicolumn{2}{|c|}{ Focused on plaintiff } & \multicolumn{2}{|c|}{ Focused on defendant } \\
\hline & 3,879 & $23.70 \%$ & 3,827 & $23.40 \%$ & 2,670 & $20.00 \%$ & 2,627 & $19.40 \%$ \\
\hline 2 depth (indirect citation) & 4,157 & $25.40 \%$ & 4,109 & $25.10 \%$ & 2,777 & $21.00 \%$ & 2,731 & $20.10 \%$ \\
\hline 3 depth (indirect citation) & 3,998 & $24.50 \%$ & 33 & $0.20 \%$ & 2,620 & $20.00 \%$ & 40 & $0.30 \%$ \\
\hline Sum & 5,549 & $33.90 \%$ & 5,019 & $30.70 \%$ & 3,540 & $27.00 \%$ & 3,266 & $24.10 \%$ \\
\hline
\end{tabular}

Table 3: All citing patent document about litigated patents

\begin{tabular}{|c|c|c|c|c|c|c|}
\hline & \multirow{2}{*}{$\begin{array}{c}\text { Patent with } \\
\text { citations among } \\
\text { litigated patents }\end{array}$} & \multicolumn{2}{|c|}{$\begin{array}{l}\text { Patent documents with } \\
\text { citations to litigated patents }\end{array}$} & \multicolumn{2}{|c|}{$\begin{array}{l}\text { Litigated Patent documents with } \\
\text { citations to litigated patents }\end{array}$} & \multirow{2}{*}{$\begin{array}{l}\text { Percent } \\
\text { (b)/(a) }\end{array}$} \\
\hline & & Average (a) & S.D. & Average (b) & S.D & \\
\hline 1 depth & 12,291 & 31.62 & 50.21 & 15.26 & 27.71 & $48 \%$ \\
\hline 2 depth & 13,368 & 236.06 & 623.54 & 114.82 & 318.91 & $49 \%$ \\
\hline 3 depth & 12,119 & 1118.06 & 3714.41 & 571.55 & 1942.23 & $51 \%$ \\
\hline
\end{tabular}

application of patent $X$. In this study, the frequency of latent citation $L C_{k}$ is calculated as shown in Eq. (4). It was also calculated by two aspects that one utilized forward citations of plaintiffs and backward citations of defendant.

$$
\begin{gathered}
{\left[\varepsilon_{i j k}\right]_{M \times N \times L},} \\
\text { where } \varepsilon_{i j k}=\left\{\begin{array}{c}
1 \quad Q_{i} \text { cites } R_{k} \text { and } P_{j} \text { cites } R_{k} \\
\text { when } T\left(Q_{i}\right)<T\left(P_{j}\right) \\
0 \quad \text { otherwise }
\end{array}\right. \\
L C_{k}=\sum_{i=1}^{k} \varepsilon_{i j k}, \quad 1 \leq k \leq L
\end{gathered}
$$

\section{Analysis}

First, the relation between litigated patents and in/direct citations were analyzed through the number of patents and the number of litigations (Table 2). On account of the different numbers of plaintiffs and defendants, respective analyses were conducted and arranged. As shown in Table 2 that explores the number of litigated patents, the number of plaintiffs' patents directly cited by defendants by the plaintiff's side is 3,879 as $23.7 \%$ compared to all 16,347 patents for analysis, 2 depth citations are 4,157 as $25.4 \%$, and 3 depth citations are 3,998 as $24.5 \%$ compared to all patents. However, these numbers have duplicated counts, thus we observed the sum of $1,2,3$ depth citations so as to exclude these duplicated counts and that is 5,549 as $33.9 \%$. In aspect of defendant, it appeared that indirect citation is $23.4 \%, 2$ depth citation is $25.1 \%, 3$ depth citation is $0.2 \%$ and the sum of all citations that exclude duplicated documents is 5,019 as $30.7 \%$. Consequently, the case of the number of citing patents in both aspects of plaintiff and defendant was shown that the sum of direct and indirect citations is more than direct citations $7 \%$ more in aspect of plaintiff and $10 \%$ more in aspect of defendant. This result of analysis represents the possibility for the relation between indirect citations and patent litigations.

In order to reconfirm the result shown in Table 2, the number of litigations of defendants citing plaintiffs was explored and the number of 1 depth citation which defendants directly cite plaintiffs was found 2,670 or $20 \%$. 2 depth citation and 3 depth citation are each 2,777 and 2,620 that shows similar or higher ratio with 1 depth citation and the sum of 1, 2, and 3 depths is 3,540 or $27 \%$ of all litigations. Likewise, in defendant's aspect the number of 2 depth citations, which is 2,731 or $20.1 \%$, exceeds the number of direct citations, which are 2,626 or $19.4 \%$. On the other hand, the number of 3 depth citation has a small value of 40 or $0.3 \%$, although the total aggregate of 1,2 , and 3 depth was larger than that of direct citation, 3,266 or $23.1 \%$. This renders that indirect citations have significant meaning in patent litigations more than the result obtained from observing the number of patent itself.

As aforementioned, the relationship between litigated patents was analyzed and the frequency of litigations regarding patents that cited litigated patents was further analyzed. As shown in Table 2, the number of citations occurred out of 16,347 is 12,291 in depth 1, 13,368 in depth 2, and 12,119 in depth 3. Additionally there occurred 31.62, 236.06, and 1118.06 citations for each depth on average for a single litigated patent with the average ratio of actual litigation occurrence of $49 \%$. 
Lastly, an interesting result was drawn from the analysis of litigations between patent in latent citing relationship based on the number of patents (Table 3). Out of the total number of patents, 5,201, 32\% of patents have gone into litigation. Considering such number is $8 \%$ higher in frequency compared to number of litigations in in/direct citation relationship, 3,879 or $23.7 \%$, various approaches for study of relationship between litigations and citations are required. Furthermore, the sum of in/direct citations and latent citations reveals that about $60 \%$ of litigated patents formed citation relationship. As arranged in the Table 3, litigation between patents in latent citing relationship has relatively high frequency of the number of plaintiffs, defendants, and litigations and thus denotes much significance.

\section{Discussion}

This study defines three kinds of citations in references to patent documents, and empirically analyzed the relationship between these citations and patent litigation between firms based on U.S. patent documents and patent litigation information of WesLaw. This study found that direct citations are related to litigations corresponding with the result of Lanjouw and Schakeman(1997) [10], with the indirect citations noted $10 \%$ more than direct citations in the number of litigated patents. Moreover, latent citations appeared to be $30 \%$ more, implicating in/direct and latent citations are important factors in studying patent litigations. Unlike previous studies which did not take into consideration about latent citations, this study presents its significance. Hence it is deemed that the study of latent citations will be essential in future research.

Through these experiments several perspectives have been uncovered. First, citation has been applied by numerous researchers and practitioners as patent indicator, whose objective was to quantitatively measure values at an aspect of an organization that owns citing or cited patent. But this study was conducted based on citations which recognized relationship between both parties, thus performing qualitative analysis via litigation data. Furthermore the study suggests diverse applications via analysis of not only direct relationship between citation by both parties citing and being cited, but indirect relationship as well.

In other words, this study didn't deal with qualitative patent indicators based on citation because this study concentrates on subdivision of patent citations and analysis of relation between organizations through these various aspects of citations. Most patent indicators related to citation were developed considering only direct citations, so that more interesting patent indicators can be developed regarding indirect citations and latent citations introduced in this study. Several researchers suggested weighted indirect citations as practicable patent indicators [26].

\section{Conclusion}

Recently patent litigations are explosively increased. Therefore this paper suggested that firms should endeavor to grasp the various relations such as direct, indirect, and latent citation related patents to frequently litigated patents or their assignees in order to manage the litigation risk and to prevent litigation from spoiling their business. Furthermore, when a firm takeovers other firm or patent for the purpose of either suing competitor or avoiding litigation, the firm should take deserves the fullest consideration of the various aspect of relation between firms indirect citations and latent citations from the result of this study. For instance, it was reported that Google which is the largest firm invested in internet search acquired Motorola Mobility for patent disputes and then IT firms' acquisition and merger for patent disputes started in earnest. In this movement, the important factor is the number of patent of firm's own in target technology fields, e.g. Google acquired Motorola Mobility because of its about 20,000 patents in related technology [28]. In this context, it will be more efficient that diverse citation relation with that competitor owned patents, was considered.

In spite of these findings, this research has certain limitations. First, because citations proposed in this study were shown to be highly related to litigated patents, overall information of general litigated citations were not considered and therefore generalization ought to be avoided. Particularly in the case of citation information, backward citation information is recorded in the citing documents. The citation information was supplied by PatentPia.com excepting the case where the document was not found in its database. Hence the information less than the backward citation information recorded in the aforementioned patent has been analyzed.

Second, a patent assignee and a patentee recorded in a patent document may be discrepant due to the fact that a patent may be assigned more than once. Accordingly, the results of analyzing plaintiffs and defendants mentioned in this study are conceivably different in actual situations. Moreover, it is known that one of the causes of patent assignment is ascribed to patent litigation and its defenses $[29,30,31]$. Studying the cause of the patent assignment based on information about patent assignment and litigations in further study will yield more promising results.

Third, according to the litigation information provided by WestLaw includes only the plaintiff's patent whereas not include that of the defendant's. Defendant's patent information is not discussed in the litigation as the main purpose is to exhibit how defendant's particular technology or product infringed upon plaintiff's patent. Therefore this study has assumed that the technology or the core technology of the product is in defendant's possession and analyzed the citing relationship of all the patents in defendant's possession. Because the defendant may not possess the patent on the technology or the 
product, the result of this research has limited to generalize.

Finally, Wartburg et al. (2005) referred to patent family citations, where a patent family cites another patent family and vice versa [14]. A patent family is the same invention disclosed by a common inventor(s) and patented in more than one country [32]. However this was not analyzed in this study due to the lack of family citation data, thereby leaving a room of expectation for an interesting result that could have been attained in future research considering an addition of litigated patent family citation.

\section{References}

[1] K. Blind, J. Edler, R. Frietsch, and U. Schmoch, Motives to patent: empirical evidence from Germany, Research Policy, 35, 655-672 (2006).

[2] H. Ernst, Patent portfolios for strategic R\&D planning, Journal of Engineering and Technology Management, 15, 279-308 (1998).

[3] S.-J. Liu, and J. Shyu, Strategic planning for technology development with patent analysis, Int. J. Technology Management, 13, 661-680 (1997).

[4] The Economist, 21 Oct. 2010, http://www.economist.com/node/17309237 (Accessed 02 July 2012).

[5] The Economist, 19 Dec. 2011, http://www.economist.com/node/21542005 (Accessed 02 July 2012).

[6] The Gardian, $01 \quad$ Nov. 2010, http://www.guardian.co.uk/technology/log/2010/nov/01/smartphone-patent-lawsuits-diagram (Accessed 02 July 2012).

[7] Y. Lai, and H. Che, Evaluating patents using damage awards of infringement lawsuits: A case study, Journal of Engineering \& Technology Management, 26, 167-180 (2009).

[8] J. Bessen, and M.J. Meurer, Lessons for patent policy from empirical research on patent litigation, Boston Univ. School of Law Working Paper. 05-22, Lewis \& Clark Law Review, 9, 1-27 (2005).

[9] R.E. Thomas, Vanquishing Copyright Pirates and Patent Trolls: The Divergent Evolution of Copyright and Patent Laws, American Business Law Journal, 43, 689-739 (2006).

[10] J.O. Lanjouw, and M. Schankerman, Stylized Facts on Patent Litigation: Value, Scope and Ownership, NBER Working paper, 6297, (1997).

[11] D. Somaya, Strategic determinants of decisions not to settle patent litigation, Strategic Management Journal, 24, 17-38 (2003).

[12] K. Cremers, Determinants of Patent Litigation in Germany, Centre for European Economic Research, Discussion Paper, No. 04-72 (2004).

[13] A.G. Kim, N.W. Partee, T.J. Reynolds, and M.A. Santamaria, Patent litigation risk-scoring model, IEEE Systems and Information Design Symposium, University of Virginia, USA, (2002).

[14] I.V. Wartburg, T. Teichert, and K. Rost, Inventive progress measured by multi-stage patent citation analysis, Research Policy, 34, 1591-1607 (2005).
[15] E. Duguet, and M. MacGarvie, How well do patent citations measure flows of technology? Evidence from French innovation surveys, Economics of Innovation and New Technology, 14, 375-393 (2005).

[16] A.C. Marco, The option value of patent litigation: Theory and evidence, Review of Financial Economics, 14, 323-351 (2005).

[17] M. Cockburn, and M. MacGarvie, Entry, Exit and Patenting in the Software Industry, NBER Working Paper, 12563, (2006).

[18] D. Harhoff, F.M. Scherer, and K. Vopel, Citations, family size, opposition and the value of patent rights, Research Policy, 32, 1343-1363 (2003).

[19] M. Trajtenberg, A penny for your quotes: patent citations and the value of inventions, The RAND Journal of Economics, 21, 172-187 (1990).

[20] M. Hirschey, and V.J. Richardson, Valuation effects of patent quality: A comparison for Japanese and U.S.firms, Pacific-Basin Finance Journal, 9, 65-82 (2001).

[21] S.G. Wang, Factors to evaluate a patent in addition to citations, Scientometrics, 71, 509-522 (2007).

[22] Karki M.M.S., Patent Citation Analysis: A Policy Analysis Tool, World patent Information, 19, 269-272 (1997).

[23] C.C. Pegels, and M.V. Thimmurthy, The impact of Technology Strategy on Firm Performance, IEEE Transactions on Engineering Management, 43, 246-249 (1996).

[24] US. Department of Commerce, The New Innovations Global Patenting Trends in Five Sectors, (1998).

[25] J.O. Lanjouw, and M. Schankerman, Characteristics of Patent Litigation: A Window on Competition, The RAND Journal of Economics, 32, 129-151 (2001).

[26] G. Atallah, and G. Rodriguez, Indirect patent citations, Scientometrics, 67, 437-465 (2006).

[27] Y. Lee, I. Kim, and S. Choi, US PATENT publication number: US2004/0133433 A1, (2004).

[28] CNET, 26 Sep., 2011,

http://news.cnet.com/8301-1035_3-20092362-94/google-to-buy-motorola-mobility-for-\%2012.5b/ (Accessed 21 September 2011).

[29] G. Fort, and D.L. Jones, Buyer Beware: When 'All Rights' Doesn't Mean What You Think, Patent Strategy \& Management, 7, (2006).

[30] J.F. McDonough III, The Myth of the Patent Troll: An Alternative View of the Function of Patent Dealers in an Idea Economy, Emory Law Journal, 56, 189-228 (2006).

[31] J. Rantanen, Slaying the troll: litigation as an effective strategy against patent threats, Santa Clara Computer and High - Technology Law Journal, 23, (2006).

[32] USPTO, $26 \quad$ Sep. 2011, http://www.uspto.gov/main/glossary/\#patentfamily (Accessed 08 July 2011). 


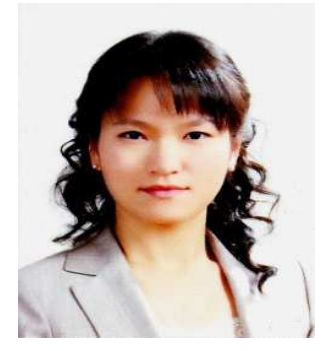

Jiyoun Lim received the Bachelors degree in industrial engineering at KAIST, the Masters degree in industrial systems and engineering at KAIST in 2007 and Ph. D degree in industrial systems and engineering at KAIST in 2013. She is currently a researcher in SW/Contents future research team at ETRI. Her research interests are in the areas of technology management and data analysis for future ICT technology. 